\title{
A Point Mutation in the Polymerase of Potato virus $Y$ Confers Virulence Toward the Pvr4 Resistance of Pepper and a High Competitiveness Cost in Susceptible Cultivar
}

\author{
Bérenger Janzac, ${ }^{1,2}$ Josselin Montarry, ${ }^{1}$ Alain Palloix, ${ }^{2}$ Olivier Navaud, ${ }^{3}$ and Benoît Moury ${ }^{1}$ \\ ${ }^{1}$ INRA, UR407 Pathologie Végétale, F-84140 Montfavet, France; ${ }^{2}$ INRA, UR1052 Génétique et Amélioration des Fruits \\ et Légumes, F-84140 Montfavet, France; ${ }^{3}$ INRA, UMR441 Laboratoire des Interactions Plantes Microorganismes, F-31326, \\ Castanet-Tolosan, France
}

Submitted 12 February 2010. Accepted 17 February 2010.

To understand why the Pvr4 resistance of pepper against Potyvirus spp. remained durable in field conditions while virulent Potato virus $Y$ (PVY) variants could be selected in the laboratory, we studied the molecular mechanisms which generated these variants and the consequences on viral fitness. Using a reverse genetics approach with an infectious cDNA clone of PVY, we found that the region coding for the NIb protein (RNA-dependent RNA polymerase) of PVY was the avirulence factor corresponding to Pvr4 and that a single nonsynonymous nucleotide substitution in that region, an adenosine to guanosine substitution at position 8,424 of the PVY genome $\left(\mathrm{A}_{\mathbf{8 4 2 4}} \mathrm{G}\right)$, was sufficient for virulence. This substitution imposed a high competitiveness cost to the virus against an avirulent PVY variant in plants devoid of $P v r 4$. In addition, during serial passages in susceptible pepper plants, the only observed possibility of the virulent mutant to increase its fitness was through the $G_{\mathbf{8 4 2 4}} A$ reversion, strengthening the high durability potential of the Pvr4 resistance. This is in accordance with the fact that the NIb protein is one of the most constrained proteins expressed by the PVY genome and, more generally, by Potyvirus spp., and with a previously developed model predicting the durability of virus resistances as a function of the evolutionary constraint applied on corresponding avirulence factors.

The high mutation rate observed in RNA viruses, which is $10^{4}$ to $10^{5}$ higher than that of their hosts (Drake and Holland 1999), and their short replication time often result in a rapid evolution, permitting adaptation to different environmental pressures (García-Arenal et al. 2001). In particular, plant resistances used to protect crops from viral diseases impose strong selective pressures that can result in the emergence of adapted virus variants. Such resistance "breakdowns" involve mutations in specific regions of the virus genome or of virus-encoded proteins called avirulence (or virulence) factors. Identification of

Corresponding author: Benoît Moury; Telephone: +33(0)4 32722816 . Fax: +33(0)4 327228 42; E-mail: Benoit.Moury@avignon.inra.fr

* The $\boldsymbol{e}$-Xtra logo stands for "electronic extra" and indicates that two supplementary tables and one supplementary figure are published online.

This article is in the public domain and not copyrightable. It may be freely reprinted with customary crediting of the source. The American Phytopathological Society, 2010. the virus avirulence factors, of the mutations in these factors that cause virulence, and of their consequences on virus fitness provides crucial data to understand and predict the relative durability of plant resistance genes. For example, it was proposed that resistance durability to viruses could be partly a consequence of the number of mutations in the virus genome required for shifts in virulence (Harrison 2002) or of the constraints imposed on amino acid substitutions in the virus avirulence factors (Janzac et al. 2009a). Because viruses have small genomes coding for multifunctional proteins, often with overlapping reading frames, even a small number of nucleotide changes associated with virulence may have strong negative effects on their fitness in plant genotypes devoid of the resistance gene (Jenner et al. 2002; Carrasco et al. 2007). The measure of these "virulence costs", though still rare in plant viruses, is important both to understand the mechanisms of plant-pathogen coevolution (Salathé et al. 2005) and to design strategies aiming at the durable use of resistance genes (Vera-Cruz et al. 2000; Leach et al. 2001).

In pepper, several genes for resistance to Potyvirus spp. were exploited by breeders (Kyle and Palloix 1997). The dominant Pvr4 gene was mapped on chromosome P10 of the consensus map of pepper (Paran et al. 2004) and presents particular interest because it possesses the largest spectrum of action known thus far, controlling resistance to members of six Potyvirus spp. (Janzac et al. 2009b), and remains effective after intensive deployment of many $F_{1}$ hybrid cultivars of sweet pepper for approximately 20 years (Dogimont et al. 1996; Janzac et al. 2009b). Although no Potato virus Y (PVY) isolate virulent toward Pvr4 has been observed in the field, graft-inoculations in laboratory conditions recently allowed selecting for such isolates (Janzac et al. 2009b). In this article, using these latter isolates, we identified the genetic determinant of PVY virulence toward Pvr4 and the consequences of a virulence mutation on PVY competitiveness with the aim to explain the high durability of the Pvr4 gene.

\section{RESULTS}

A candidate amino acid substitution for PVY virulence toward Pvr4.

A reverse genetics strategy was used to identify the mutations involved in PVY virulence toward the Pvr4 resistance. The first step consisted of the identification of nucleotide changes between the genomes of the cDNA clone of the avirulent 
SON41p isolate and its virulent variants. Several nucleotide substitutions were observed between the original SON41p sequence and sequences obtained from cloned cDNA fragments of the virulent variants (data not shown). However, among all these nucleotide substitutions, only one, the adenosine-toguanosine substitution at position $8,424\left(\mathrm{~A}_{8424} \mathrm{G}\right)$, was shared by all three independently selected virulent variants. Such parallel evolution makes the $\mathrm{A}_{8424} \mathrm{G}$ substitution an interesting candidate for virulence toward Pvr4. This nucleotide substitution corresponds to the replacement of the lysine at position 472 of the NIb protein, the viral RNA-dependent RNA polymerase (RdRp), of SON41p by a glutamic acid in variants G1, $\mathrm{G} 2$, and $\mathrm{G} 3$ ( $\mathrm{K}_{472} \mathrm{E}$ substitution) (Table 1). For all sequences of cDNA clones corresponding to the NIb cistron of variants G1 to G3, additional nonsynonymous nucleotide substitutions were observed compared with SON41p (data not shown). However, when reverse-transcription polymerase chain reaction (RT-PCR) products obtained from these variants were sequenced directly, fewer substitutions were observed (Table 1). Notably, for the $\mathrm{G} 3$ virulent variant, the $\mathrm{K}_{472} \mathrm{E}$ substitution was the sole amino acid difference observed in the NIb protein compared with SON41p (Table 1). Consequently, we tested the hypothesis that this amino acid substitution was sufficient for PVY virulence toward Pvr4.

\section{The $A_{8424} G$ substitution in the NIb cistron of PVY confers virulence toward Pvr4.}

In order to determine whether the $\mathrm{A}_{8424} \mathrm{G}$ substitution observed in the NIb cistron of virulent variants of SON41p confers virulence toward the Pvr4 resistance, we constructed a mutant of SON41p, named SON41p- $\mathrm{A}_{8424} \mathrm{G}$, harboring that

Table 1. Amino acid substitutions in the NIb of virulent variants of SON41p deduced from direct sequencing of reverse-transcription polymerase chain reaction products

\begin{tabular}{llcccc}
\hline & & \multicolumn{4}{c}{ Amino acid positions $^{\mathbf{a}}$} \\
\cline { 3 - 6 } PVY isolate $^{\mathbf{b}}$ & Virulence $^{\mathbf{c}}$ & $\mathbf{8 8}$ & $\mathbf{2 3 4}$ & $\mathbf{3 9 0}$ & $\mathbf{4 7 2}$ \\
\hline SON41p & Avirulent & $\mathrm{D}$ & $\mathrm{L}$ & $\mathrm{E}$ & $\mathrm{K}$ \\
SON41p-G1 & Virulent & $\mathrm{N}$ & $\mathrm{H}$ & $\ldots$ & $\mathrm{E}$ \\
SON41p-G2 & Virulent & $\ldots$ & $\ldots$ & $\mathrm{G}$ & $\mathrm{E}$ \\
SON41p-G3 & Virulent & $\ldots$ & $\ldots$ & $\ldots$ & $\mathrm{E}$ \\
\hline
\end{tabular}

${ }^{a}$ Amino acid positions and substitutions in the NIb protein.

${ }^{\mathrm{b}} \mathrm{PVY}=$ Potato virus $Y$.

${ }^{\mathrm{c}}$ Virulence toward the Pvr4 resistance gene. mutation using site-directed mutagenesis. Similarly to the G1, G2, and G3 PVY variants, the SON41p- $\mathrm{A}_{8424} \mathrm{G}$ mutant induced mosaic symptoms in apical uninoculated leaves of all the inoculated plants of pepper genotypes Yolo Wonder (YW) and W4 ( $n=50$ for each), which are the reference lines for PVY susceptibility and for the Pvr4 gene, respectively, and PVY was detected in these organs at 15 days post inoculation (dpi) by double-antibody sandwich enzyme-linked immunosorbent assay (DAS-ELISA). By contrast, the SON41p clone induced symptoms and was detected by DAS-ELISA at the systemic level only in YW plants. In W4 plants, SON41p induced no symptoms and was not detected by DAS-ELISA or RT-PCR at either the systemic level or in inoculated organs, as described previously (Janzac et al. 2009b). Sequences of the NIb cistron of the viral progenies resulting from the infection of W4 plants by SON41p- $\mathrm{A}_{8424} \mathrm{G}$ were determined and found to be identical to the original mutant cDNA clone. These results provide evidence that the genome region encoding the NIb protein is the avirulence factor of PVY toward Pvr4, and that one nucleotide substitution at position 8,424 suffices to confer virulence.

\section{The $A_{8424} G$ substitution in the NIb cistron strongly decreases the competitiveness of PVY in susceptible pepper plants.}

The efficiency of accumulation of SON41p and SON41p$\mathrm{A}_{8424} \mathrm{G}$ were estimated in both single-inoculation and competition experiments in the pepper line YW, which does not carry the Pvr4 gene. In single-inoculation experiments, the SON41p- $\mathrm{A}_{8424} \mathrm{G}$ mutant accumulated at a higher level $(50 \%$ more) than SON41p at $15 \mathrm{dpi}$ (analysis of variance [ANOVA], $P$ value $=0.025$; Kruskal-Wallis test, $P$ value $=0.023)($ Fig. 1A). However, no significant accumulation differences were observed in YW between these two PVY variants at $30 \mathrm{dpi}$ (ANOVA and Kruskal-Wallis test, $P$ values $>0.4$ ) (Fig. 1A). The ability of SON41p- $\mathrm{A}_{8424} \mathrm{G}$ to accumulate in competition with SON41p was measured in YW plants inoculated with a mixture of these variants at $1: 1$ or $1: 4$ initial ratios (Fig. 1B; Supplementary Table S1). For each initial ratio, a large and continuous decrease of the proportion of the virulent variant in the total virus population was observed. At $15 \mathrm{dpi}$, the proportion of the SON41p- $\mathrm{A}_{8424} \mathrm{G}$ mutant in the population was significantly reduced compared with the initial inocula (Fisher exact tests, $P$ values $<0.003$ ) (Fig. 1B). The same trend was observed when comparing the proportion of SON41p- $\mathrm{A}_{8424} \mathrm{G}$ at 30 dpi with that measured at 15 dpi (Kruskal-Wallis test, $P$
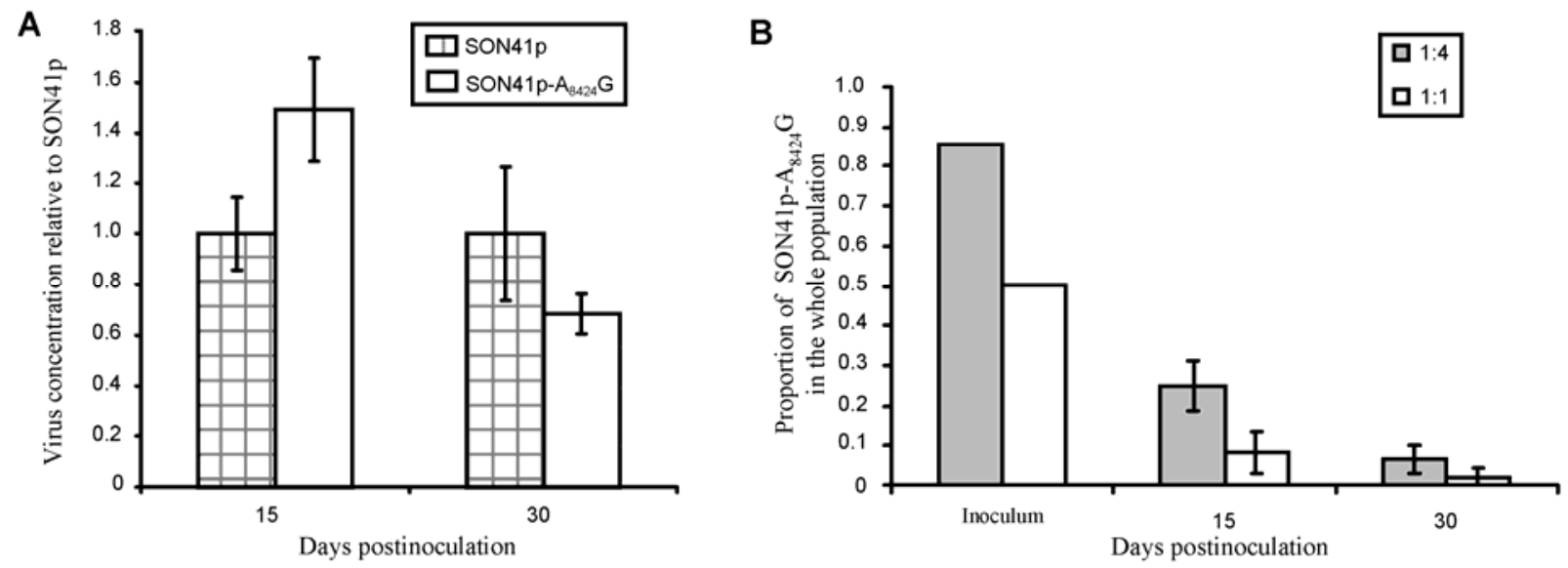

Fig. 1. Relative accumulation of the SON41p-adenosine-to-guanosine substitution at position 8,424 (A $\left.\mathrm{A}_{8424} \mathrm{G}\right)$ and $\mathrm{SON} 41 \mathrm{p}$ Potato virus $Y$ variants in Yolo Wonder (YW) plants. A, Single-inoculation experiments. Relative concentration of the virus variants was assessed by semiquantitative double-antibody sandwich enzyme-linked immunosorbent assay (DAS-ELISA) (Moury et al. 2004). B, Competition experiments. Co-inoculation of YW plants was performed with initial inoculum ratio of 1:1 or 1:4 of SON41p and SON41p-A ${ }_{8424} \mathrm{G}$, respectively, as assessed by semiquantitative DAS-ELISA. The proportion of each variant in the viral populations was estimated by dCAPS analysis. Standard errors are shown. 
values $\leq 0.026$ ). At $30 \mathrm{dpi}$, the SON41p- $\mathrm{A}_{8424} \mathrm{G}$ mutant represented less than $7 \%$ of the total virus population in all YW plants (4.4\% on average) (Fig. 1B). The decrease rate of the proportion of $\mathrm{SON} 41 \mathrm{p}-\mathrm{A}_{8424} \mathrm{G}$ in the total population was remarkably similar for both initial conditions. For example, between 15 and $30 \mathrm{dpi}$, its proportion in the total virus population was divided by 3.71 and 3.77 for YW plants inoculated with a $1: 4$ and $1: 1$ initial ratio of the variants, respectively.

The fitness cost associated with the $\mathrm{A}_{8424} \mathrm{G}$ virulence mutation was confirmed by longer-term experiments involving eight serial passages of PVY in YW plants. Five evolution lineages were performed with an initial virus population composed of the SON41p- $\mathrm{A}_{8424} \mathrm{G}$ mutant alone. In one of five independent evolution lineages, the SON41p- $\mathrm{A}_{8424} \mathrm{G}$ variant had lost its virulence toward Pvr4 after the sixth passage. In three additional evolution lineages, the virulence was lost after the eighth passage whereas, in the fifth evolution lineage, the virulence was maintained after the eighth passage (Table 2). The consensus sequence of the NIb cistron of the four PVY populations that lost their virulence revealed the presence of an adenosine at position 8,424 of the genome (corresponding to codon 472 of the NIb cistron), indicating that a mutational reversion occurred independently at this position in all these populations. Analysis of the sequence chromatogram of the fifth viral population, which was still virulent toward Pvr4, showed that an adenosine was predominant at position 8,424 but a guanosine was also present in lower proportions, indicating that the reversion was only partial. Two synonymous substitutions were also noticed in these five PVY populations at codons 296 and 298 of the NIb cistron (Table 2). These substitutions were already present in the initial SON41p- $\mathrm{A}_{8424} \mathrm{G}$ inoculum which was prepared from infected Nicotiana clevelandii plants (Table 2). Ten independent evolution lineages were also performed in YW with virus populations composed initially of a 1:1 ratio of SON41p$\mathrm{A}_{8424} \mathrm{G}$ and SON41p. As soon as after the sixth passage, the 10 PVY populations had lost their virulence toward Pvr4 and an adenosine was present at position 8,424 of the genome of these
10 populations (Table 2 ). The fact that the two synonymous substitutions detected in the initial SON41p- $\mathrm{A}_{8424} \mathrm{G}$ inoculum at codons 296 and 298 of the NIb cistron were not observed in these populations (Table 2) indicates that the loss of the virulence toward Pvr4 in these populations was due to the counter selection of SON41p- $\mathrm{A}_{8424} \mathrm{G}$ in competition with SON41p during the passages rather than to $\mathrm{G}_{8424} \mathrm{~A}$ reversions in the genome of SON41p- $\mathrm{A}_{8424} \mathrm{G}$. This also indicates that the synonymous substitutions observed at codon positions 296 and 298 have few, if any, compensatory effects on the virus competitiveness, because they did not avoid the virulent variant to be eliminated from the virus population between the third and the sixth passage in YW (Table 2). Outside these three codons (i.e., codon 472 involved in virulence and codons 296 and 298), only two different synonymous substitutions were fixed in the NIb cistron of 2 of the 15 independent lineages (at codons 333 and 388) (Table 2), none of which were associated with a Pvr4-virulent population. Consequently, there was no evidence of compensatory mutations in the NIb cistron of any of these 15 PVY populations. Altogether, these data revealed that the only solution for the SON41p- $\mathrm{A}_{8424} \mathrm{G}$ mutant to recover fitness was through the $\mathrm{G}_{8424} \mathrm{~A}$ mutational reversion that simultaneously caused a virulence reversion.

\section{Comparison of the three-dimensional structures} of the NIb proteins of different Potyvirus spp. and variants.

The overall structure of the Potyvirus NIb protein can be described using an analogy to a right hand, with fingers, palm, and thumb domains and additional $\mathrm{N}$-terminal and $\mathrm{C}$-terminal domains (Bruenn 2003). Amino acid sequence alignments showed that the substitution $\mathrm{K}_{472} \mathrm{E}$ in the NIb protein of PVY virulent mutants is unique among PVY isolates but also among the different Potyvirus spp. which infect pepper. It is located in the highly conserved amino acid motif "GKAPY" which corresponds to amino acids 471 to 475 of PVY (Fig. 2). Analysis of the predicted secondary structure of the PVY NIb protein showed that the "GKAPY" motif is included in a loop struc-

Table 2. Evolution of the virulence toward the Pvr4 resistance gene and of the consensus sequence of the NIb cistron of Potato virus $Y$ (PVY) populations after serial passages in Yolo Wonder (YW) plants, devoid of $P v r 4^{\text {a }}$

\begin{tabular}{|c|c|c|c|c|c|c|c|c|}
\hline \multirow[b]{2}{*}{ Population or lineage $^{\mathrm{d}}$} & \multicolumn{3}{|c|}{ Virulence toward Pvr4 after ${ }^{\mathrm{b}}$} & \multicolumn{5}{|c|}{ Codon positions and nucleotide differences ${ }^{c}$} \\
\hline & 3 passages & 6 passages & 8 passages & 296 & 298 & 333 & 388 & 472 \\
\hline SON41p original inoculum & $\ldots$ & $\ldots$ & $\ldots$ & ACT & GAT & AAG & AAC & AAG \\
\hline $\mathrm{A}_{8424} \mathrm{G}$ original inoculum & $\ldots$ & $\ldots$ & $\ldots$ & ACA & GAC & $\ldots$ & $\ldots$ & GAG \\
\hline \multicolumn{9}{|l|}{$\mathrm{A}_{8424} \mathrm{G}$ lineage } \\
\hline No. 1 & Vir & Vir & Avir & ACA & GAC & $\ldots$ & AAT & $\ldots$ \\
\hline No. 2 & Vir & Vir & Avir & ACA & GAC & $\ldots$ & $\ldots$ & $\ldots$ \\
\hline No. 3 & Vir & Avir & Avir & $\mathrm{ACA}$ & GAC & $\ldots$ & $\ldots$ & $\ldots$ \\
\hline No. 4 & Vir & Vir & Avir & ACA & GAC & $\ldots$ & $\ldots$ & $\ldots$ \\
\hline No. 5 & Vir & Vir & Vir & ACA & GAC & $\ldots$ & $\ldots$ & GAG \\
\hline \multicolumn{9}{|l|}{$\mathrm{A}_{8424} \mathrm{G}+\mathrm{SON} 41 \mathrm{p}$ lineage } \\
\hline No. 1 & Vir & Avir & Avir & $\ldots$ & $\ldots$ & $\ldots$ & $\ldots$ & $\ldots$ \\
\hline No. 2 & Vir & Avir & Avir & $\ldots$ & $\ldots$ & $\ldots$ & $\ldots$ & $\ldots$ \\
\hline No. 3 & Vir & Avir & Avir & $\ldots$ & $\ldots$ & $\ldots$ & $\ldots$ & $\ldots$ \\
\hline No. 4 & Vir & Avir & Avir & $\ldots$ & $\ldots$ & $\ldots$ & $\ldots$ & $\ldots$ \\
\hline No. 5 & Vir & Avir & Avir & $\ldots$ & $\ldots$ & $\ldots$ & $\ldots$ & $\ldots$ \\
\hline No. 6 & Vir & Avir & Avir & $\ldots$ & $\ldots$ & $\ldots$ & $\ldots$ & $\ldots$ \\
\hline No. 7 & Vir & Avir & Avir & $\ldots$ & $\ldots$ & $\ldots$ & $\ldots$ & $\ldots$ \\
\hline No. 8 & Vir & Avir & Avir & $\ldots$ & $\ldots$ & $\ldots$ & $\ldots$ & $\ldots$ \\
\hline No. 9 & Vir & Avir & Avir & $\ldots$ & $\ldots$ & $\ldots$ & $\ldots$ & $\ldots$ \\
\hline No. 10 & Vir & Avir & Avir & $\ldots$ & $\ldots$ & AAA & $\ldots$ & $\ldots$ \\
\hline
\end{tabular}

${ }^{a}$ Nucleotides highlighted in gray correspond to differences from the sequence of the NIb cistron of SON41p. Underlined, bold codons correspond to nonsynonymous substitutions.

${ }^{\mathrm{b}}$ Virulence toward Pvr4 after different numbers of passages in YW was assessed by inoculation to $10 \mathrm{~W} 4$ pepper plants. Vir: virulent population (10 of 10 plants were infected). Avir: avirulent population (no W4 plants were infected).

${ }^{c}$ Codon positions and nucleotide differences from the sequence of the NIb cistron of SON41p. Except for the original inocula, the sequence of the NIb cistron of the PVY populations was determined after the seventh passage in YW.

${ }^{\mathrm{d}}$ PVY population or evolutionary lineage. Initial populations, composed of the SON41p-adenosine-to-guanosine substitution at position $8,424\left(\mathrm{~A}_{8424} \mathrm{G}\right)$ variant alone or mixed with SON41p at an initial 1:1 ratio, were obtained from Nicotiana clevelandii plants inoculated with PVY cDNA clones. 
ture in the "thumb" domain which is located at the C-terminal end of the protein (Fig. 2). This loop was predicted to be exposed at the surface of the protein (Supplementary Fig. S1) and functionally important using ConSeq. The thumb domain of RdRps is thought to be involved in formation of a clamp on RNA template binding, and mutations that map to the thumb in a number of RdRps confirmed that it is essential for RNA synthesis (O'Reilly and Kao 1998). The substitution of the lysine at position 472 by a glutamic acid caused a modification of the charge of the residue at this position. Both amino acids are highly polar residues but lysine is negatively charged while glutamic acid is positively charged. This substitution did not cause obvious modifications in the predicted conformation of the loop structure or of the entire thumb domain. The predicted three-dimensional structure of the NIb of Tobacco etch virus (TEV), which belongs to the group of pepper Potyvirus spp. which are not controlled by the Pvr4 gene (Janzac et al. $2009 \mathrm{~b}$ ), did not show major differences compared with that of the NIb of PVY. Notably, the thumb domain of the protein seemed relatively conserved between these two viral species and the global charge of the domain remained negative. The only modification observed between the predicted structure of the NIbs of PVY and TEV concerned the C-terminal domain. However, due to the lack of reference with the structure of the RdRp of Rabbit hemorrhagic disease virus (RHDV, genus Lagovirus) (Fig. 2) and to the flexibility of this part of the protein, the structure of the C-terminal domain could not be precisely predicted.

\section{DISCUSSION}

Much effort has been made to understand the mechanisms involved in emergence of virulent forms of pathogens because they determine the durability of plant resistances. Contrary to many major virus resistance genes that have been impaired by the emergence of virulent variants, the resistance conferred by the Pvr4 gene in pepper against Potyvirus spp. remained durable for 20 years in field conditions. Recently, PVY variants virulent toward Pvr4 have been obtained during laboratory experiments (Janzac et al. 2009b). In order to understand why the Pvr4 resistance remained durable despite the virulent PVY variants that could be selected, we studied the molecular mechanisms which generated these variants and their fitness. The use of a reverse-genetics strategy pointed out that the region cod- ing for the NIb protein (RdRp) of PVY was the avirulence factor corresponding to Pvr4. This constitutes the first example of a Potyvirus NIb cistron functioning as an avirulence factor, even though the PVY NIb cistron was found to determine particular symptoms (veinal necrosis) in tobacco lines carrying the $R k$ gene which confers resistance against root knot nematodes (Fellers et al. 2002). Our results also showed that one single nucleotide (and amino acid) substitution conferred the virulence toward Pvr4. Although direct evidence is still lacking, it is more likely that the avirulence factor corresponding to Pvr4 is the PVY NIb protein rather than the RNA segment coding for it. Indeed, almost all reported virus mutations conferring virulence toward dominant plant resistances were nonsynonymous nucleotide substitutions (Harrison 2002; Kang et al. 2005).

Many examples showed that virus adaptation to plant resistance depends on one or a few nucleotide substitutions in the virus avirulence factor (Harrison 2002; Lecoq et al. 2004). Moreover, it was observed that the smaller the number of substitutions required for virulence, the lower the durability of the corresponding resistance gene (Harrison 2002). More recently, this observation was also validated in the case of PVY adaptation to the different recessive resistance alleles at the $p v r 2$ locus in pepper. PVY adaptation to the $p v r 2^{2}$ allele, which possesses the highest resistance durability among alleles at this locus, requires at least two nucleotide substitutions in the virus VPg cistron, whereas the adaptation to other, less durable alleles at the same locus ( $p v r 2^{1}$ and $\left.p v r 2^{3}\right)$ requires only one nucleotide substitution (Ayme et al. 2007). In the case of Pvr4, the observed high durability of the resistance contrasts with the fact that only one nucleotide substitution, an adenosine-toguanosine transition, is enough to determine PVY virulence.

Although a few nucleotide substitutions are generally sufficient for evolution of plant viruses toward virulence (Harrison 2002), and in spite of their high mutation rates, resistance factors deployed against viruses generally display longer lifespans than resistances targeting other pathogens. This suggests that higher fitness costs are conferred by virulence mutations in the case of viruses even though accurate measures of such "virulence fitness costs" are lacking to test this hypothesis. Indeed, virulence fitness costs penalizing the virus capacity of replication, translocation, or transmission have been hypothesized in a number of cases (Murant et al. 1968; Pelham et al. 1970; Berzal-Herranz et al. 1995; Sacristán and García-Arenal 2008)

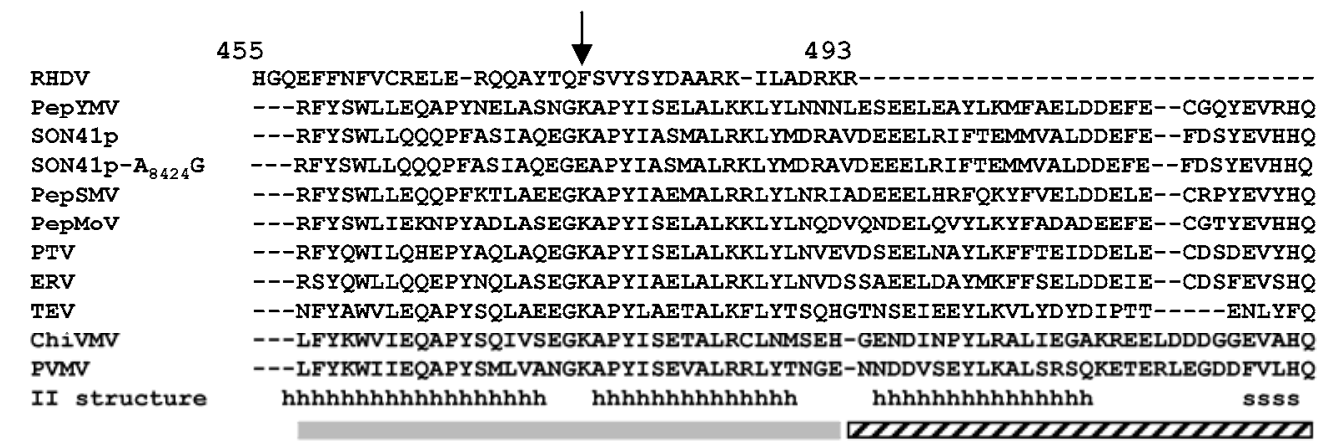

Fig. 2. Amino acid alignment of the C-terminal part of the NIb protein of pepper Potyvirus spp. and of the RNA-dependent RNA polymerase (RdRp) of Rabbit hemorrhagic disease virus (RHDV; accession number DQ205345, Protein Data Bank ID: 1khv). Pepper veinal mottle virus (PVMV; GenBank accession number AJ780966), Chilli veinal mottle virus (ChiVMV; accession number AJ237843), Tobacco etch virus (TEV; accession number M11458), and the SON41p-adenosine-to-guanosine substitution at position 8,424 $\left(\mathrm{A}_{8424} \mathrm{G}\right)$ variant of Potato virus $Y$ (PVY) infect plants carrying the Pvr4 gene whereas the SON41p isolate of PVY, Pepper mottle virus (PepMoV; accession number AF501591), Pepper severe mosaic virus (PepSMV; accession number AM181350), Pepper yellow mosaic virus (PepYMV; accession number AF348610), Peru tomato virus (PTV; accession number EU495235), and Ecuadorian rocotto virus (ERV; accession number EU495234) do not. The arrow points to the amino acid position corresponding to the replacement of lysine at position 472 by a glutamic acid $\left(\mathrm{K}_{472} \mathrm{E}\right.$ substitution) in the NIb protein of PVY which is responsible for virulence toward Pvr4. The thumb and C-terminal domains of the RNA-dependent RNA polymerase are indicated by a gray and a hatched box, respectively. Secondary structures were predicted by Promals $3 \mathrm{D}$; $\mathrm{h}=$ helix and $s=\beta$ strand. 
but fewer studies have compared virulent and avirulent isolates differing only at mutations involved in virulence with the use of viral DNA clones (Meshi et al. 1989; Culver et al. 1994; Bendahmane et al. 1995; Jenner et al. 2002). Consequently, for many comparisons, the effect of second-site mutations on the virus fitness cannot be excluded. Moreover, only Jenner and associates (2002) have compared the accumulation of virulent and avirulent virus variants in a situation of competition which reflects more realistically what happens when virulent variants appear in an avirulent viral population. However, their approach was slightly different from ours. Starting with plants co-inoculated by a virulent and an avirulent variant, they followed the proportion of plants infected by one or the other virus variant across serial passages in plants. Therefore, our study is, to our knowledge, the first one where the competitiveness of virus isolates differing only by a mutation involved in virulence was measured in individual plants. Importantly, such measures at the within-plant level are key parameters to compare the risks of breakdown between different resistance genes using modeling approaches (Moury et al. 2007; Fabre et al. 2009).

The substitution $\mathrm{A}_{8424} \mathrm{G}$ in the PVY genome imposed a high competitiveness cost to the virus in plants devoid of Pvr4. Indeed, co-inoculation of the PVY avirulent clone SON41p and the virulent mutant $\mathrm{SON} 41 \mathrm{p}-\mathrm{A}_{8424} \mathrm{G}$ in susceptible $\mathrm{YW}$ pepper plants revealed that the virulent variant reached very low percentages in the virus population at $30 \mathrm{dpi}$ (Fig. 1B). In addition, serial passages in YW showed that the only observed possibility of the SON41p- $\mathrm{A}_{8424} \mathrm{G}$ to compensate for this competitiveness cost was through the $\mathrm{G}_{8424} \mathrm{~A}$ reversion, which simultaneously caused a reversion of the virulence of the virus. Such a high fitness cost could explain why PVY virulent variants never emerged and why the $P v r 4$ resistance remained durable. Indeed, two successive steps are required for resistance breakdown to occur: i) mutation or recombination events should appear in the avirulence gene of a pathogen to generate virulent variants and ii) the fitness of these virulent variants should permit them to increase in frequency in the virus population and spread in the agroecosystem (Leach et al. 2001; Gómez et al. 2009). The first step of resistance breakdown is unlikely to occur in pepper plants carrying the Pvr4 resistance gene because PVY multiplication in these plants is extremely low. In fact, no PVY multiplication could be detected in leaves of Pvr4-carrying plants inoculated with PVY or any of five more Potyvirus spp., either by DAS-ELISA, RT-PCR (Janzac et al. 2009b), or inoculation of susceptible YW or $N$. benthamiana plants (data not shown). In this respect, Pvr4 is similar to genes controlling "extreme resistances" (ER) (Köhm et al. 1993; Hajimorad and Hill 2001). In contrast, virus multiplication and limited cell-tocell translocation was detectable in cotyledons of Pvr4-carrying plants, showing necrotic lesions typical of hypersensitive responses, after inoculation with different Potyvirus spp. and with some PVY isolates (Janzac et al. 2009b). The efficiency of the resistance in protoplasts, another characteristic of ER (Köhm et al. 1993), was not established for Pvr4 due to technical difficulties in handling pepper protoplasts (data not shown).

The Pvr4-virulent variants are much more likely to be generated in plants devoid of the Pvr4 gene. However, in such plants, they would immediately be in competition with the avirulent components of the virus population, and the strong competitiveness penalty conferred by the $A_{8424} G$ mutation would not allow virulent PVY variants to accumulate in the plants and to spread in the agroecosystem. Consequently, the high durability of the Pvr4 resistance to PVY could be due to the conjunction of i) the high level of the Pvr4 resistance toward avirulent isolates, ii) the high competitiveness cost of the virulence mutation in plants devoid of $P v r 4$, and iii) the absence or rarity of mutations in the PVY genome that could compensate for the competitiveness cost incurred by the virulent variants while maintaining their virulence toward Pvr4.

It is noteworthy that the NIb is one of the most constrained proteins of PVY (Moury et al. 2006) (i.e., it is one of the proteins in which amino acid substitutions are likely to induce the highest fitness penalties). Indeed, the ratio between the nonsynonymous and the synonymous nucleotide substitution rates ( $\omega$ ratio) (Kimura 1983) used to estimate the constraint acting on amino acid substitutions on the whole PVY NIb protein proved to be low $(\omega=0.05)$ compared with the average value of the rest of the genome $(\omega=0.11)$ (Moury et al. 2006). Janzac and associates (2009a) found that the $\omega$ ratio of virus avirulence factors was correlated with the durability of the corresponding resistances and they developed a predictive model to estimate the potential durability of a given virus resistance gene as a function of the $\omega$ ratio estimated from the corresponding avirulence factor. According to that model, the Pvr4 resistance would have a high probability $(P=0.65)$ of belonging to the most durable resistance durability class or to the two most durable among the three durability classes $(P=0.93)$. More generally, Moury and associates (2006) showed that the $\mathrm{NIb}$ protein was the second most constrained of the proteins encoded by six different Potyvirus spp. with different biological and epidemiological properties for which enough genome sequence data were available. Although it was not possible to estimate the constraint exerted on the NIb protein encoded by the other five Potyvirus spp. controlled by Pvr4 due to insufficient sequence data, this could explain the observed high durability of Pvr4 toward these five Potyvirus spp. as well.

To explain the broad spectrum of action of Pvr4, it was previously suggested that this resistance factor could recognize an elicitor structure that would be conserved among the six Potyvirus spp. controlled by Pvr4 but distinct in the other Potyvirus spp. (Janzac et al. 2009b). In PVY, we found that the substitution of one amino acid at position 472 in the NIb protein was enough to disturb recognition of the avirulence factor by the plant resistance factor. We showed that this amino acid mutation was in a highly conserved loop structure within the thumb domain of the NIb protein of pepper Potyvirus spp. The lysine to glutamic acid substitution at position 472 changed the charge of the amino acid residue but not the predicted threedimensional conformation or global surface charge of this domain of the PVY NIb protein. This result suggests that this change of amino acid charge at position 472 or minor conformation modifications in this or other domains of the NIb protein are responsible for the difference in recognition by Pvr4. The loop structure observed in the thumb domain of the NIb protein of PVY was also conserved in the NIb protein of TEV, which infects pepper plants carrying the Pvr4 gene. Moreover, no obvious modifications were observed between the predicted thumb domains of the NIb proteins of TEV and PVY. The conservation of that loop structure in avirulent and virulent PVY isolates and in other pepper Potyvirus spp. either inducing or not the Pvr4 resistance also emphasizes the structural and functional importance of this domain for virus fitness, which probably accounts for the high competitiveness cost associated with the $\mathrm{K}_{472} \mathrm{E}$ substitution.

In conclusion, our results also emphasize the relevance, at different taxonomic levels, of identifying avirulence factors in order to understand the durability of plant resistances to pathogens. At the virus isolate (SON41p) scale, it allowed the precise measure of the competitiveness cost associated with a virulence mutation. At the species (PVY) level, together with a previously developed model (Janzac et al. 2009a), it strengthens the role of the evolutionary constraint acting on the $\mathrm{NIb}$ protein as a major factor involved in the durability of Pvr4. This could also be true at the genus (Potyvirus) level because 
the NIb is one of the most constrained proteins among various Potyvirus spp. (Moury et al. 2006), although this could not be formally measured in our case because of the lack of available sequences. In addition, the relatively ancient divergence between Potyvirus spp. adapted or not to the Pvr4 resistance in pepper (Janzac et al. 2009b) suggests that this trait could have been modified only once during the evolutionary history of pepper Potyvirus spp. which, again, could be due to the high evolutionary constraint acting on this protein.

\section{MATERIALS AND METHODS}

\section{Plant and virus materials.}

Pepper (Capsicum annuum L.) lines W4 and YW were used in our experiments. W4 is a reference doubled-haploid line carrying the Pvr4 resistance gene in a susceptible genetic background (Janzac et al. 2009b), and YW is a bell pepper inbred line devoid of Potyvirus resistance genes that was used as a susceptible control in all experiments.

PVY isolate SON41p was described by Gebre-Selassie and associates (1985) and is avirulent toward Pvr4. An infectious cDNA clone of SON41p was obtained previously (Moury et al. 2004). Three variants of SON41p virulent toward Pvr4, named G1 to G3, were obtained from graft-inoculation experiments where W4 scions were grafted onto SON41p-inoculated YW rootstocks (Janzac et al. 2009b).

\section{Sequencing of PVY genome and construction of a mutated clone of SON41p.}

Overlapping RT-PCR fragments of approximately 1,000 to 2,000 bp, covering the entire genome of the virulent PVY isolates, were obtained with specific primers defined from the sequence of SON41p and were cloned into the pGEM-T Easy vector (Promega Corp., Madison, WI, U.S.A.) according to standard protocols (Sambrook et al. 1989). One to three clones were sequenced (Genome Express, Grenoble, France) for each fragment of each virulent isolate. Amino acid sequences were then aligned and compared with the sequence of SON41p (GenBank accession number AJ439544) with the Clustal W program (Thompson et al. 1994). Direct sequencing of RTPCR fragments covering the entire NIb cistron of variants G1, G2, and G3 was also performed (Supplementary Table S2).

A mutated clone of SON41p with a single adenosine-toguanosine substitution in the NIb cistron at nucleotide position 8,424 (named SON41p- $\mathrm{A}_{8424} \mathrm{G}$ ) was constructed using the QuikChange site-directed mutagenesis kit (Stratagene, La Jolla, CA, U.S.A.) as described by Ayme and associates (2006).

\section{PVY inoculation and virus detection.}

Inoculations were carried out under insect-proof greenhouse conditions. Primary inoculations with the cDNA clones SON41p and SON41p- $\mathrm{A}_{8424} \mathrm{G}$ were made by DNA-coated tungsten particle bombardments of $N$. clevelandii juvenile plants (4 weeks post sowing), because direct bombardment of pepper plants is not efficient (Moury et al. 2004). Fifty W4 and YW pepper plants were mechanically inoculated on their two cotyledons approximately 3 weeks after sowing (first-leaf stage) using crude extracts from the infected $N$. clevelandii plants according to Moury and associates (2004) in four independent experiments. Detection of the virus in the inoculated plants was performed by DAS-ELISA as described by Légnani and associates (1995) at $30 \mathrm{dpi}$.

\section{Fitness comparison of PVY variants.}

The fitness of the virulent SON41p- $\mathrm{A}_{8424} \mathrm{G}$ variant and of SON41p were compared in both single-inoculation and competition experiments in the susceptible YW genotype. Inocula of SON41p- $\mathrm{A}_{8424} \mathrm{G}$ and SON41p were calibrated using semiquantitative DAS-ELISA as shown by Ayme and associates (2006) and used separately for single inoculations or mixed for competition experiments.

For single inoculations, the relative accumulation of each variant was measured at 15 and $30 \mathrm{dpi}$ on two independent sets of $10 \mathrm{YW}$ plants inoculated by either SON41p or SON41p$\mathrm{A}_{8424} \mathrm{G}$. For each YW plant, all leaves were pooled and the relative PVY accumulation in these samples was determined by semiquantitative DAS-ELISA (Ayme et al. 2006). An ANOVA and a Kruskal-Wallis nonparametric test were performed on the relative accumulation of each variant in order to detect significant accumulation differences between the two PVY variants.

For competition experiments, inocula of SON41p and SON41p- $\mathrm{A}_{8424} \mathrm{G}$ were mixed at two ratios $(1: 1$ or $1: 4)$ based on semiquantitative DAS-ELISA and used to inoculate two independent sets of $10 \mathrm{YW}$ plants per ratio. The relative accumulation of the two PVY variants was analyzed using dCAPS analysis (Michaels and Amasino 1998; Neff et al. 1998) as shown by Ayme and associates (2006). For each inoculated YW plant, total RNAs were extracted from pools of three infected leaves with the Tri Reagent kit (Molecular Research Center Inc., Cincinnati, OH, U.S.A.) and used to amplify the entire NIb cistron by RT-PCR with primers Nib-5' and Nib-3'. The obtained DNA fragments were cloned into pGEM-T Easy as describe above and the presence of the mutation $\mathrm{A}_{8424} \mathrm{G}$ in the cloned NIb cistron was detected using the dCAPS method with primers dCAPS-5' and dCAPS- $3^{\prime}$ and the endonuclease BanII, which cleaves PCR products obtained with SON41p$\mathrm{A}_{8424} \mathrm{G}$ but not with SON41p. Fisher exact tests were used to detect significant differences in the proportions of SON41p and SON41p- $\mathrm{A}_{8424} \mathrm{G}$ between the initial state (inoculum) and infected YW plants at 15 or $30 \mathrm{dpi}$. A Kruskal-Wallis test was used to compare the relative proportions of SON41p and SON41p-A ${ }_{8424} \mathrm{G}$ at 15 and 30 dpi.

\section{Serial passages of the virulent SON41p- $\mathrm{A}_{8424} \mathrm{G}$ variant in susceptible pepper plants.}

In all, 5 independent evolution lineages were performed with an initial inoculum corresponding to the PVY variant SON41p- $\mathrm{A}_{8424} \mathrm{G}$ and 10 independent evolution lineages were performed with an initial inoculum corresponding to a $1: 1$ mixture of SON41p- $\mathrm{A}_{8424} \mathrm{G}$ and SON41p. The initial inocula were obtained from the multiplication of the two cDNA clones in $N$. clevelandii. For each of these 15 evolution lineages, eight serial passages were realized in YW plants at 3- to 4-week intervals, which corresponded to a 7-month experiment in total. For each passage, three apical leaves of infected plants were sampled and pooled to prepare inocula and two plants were inoculated per lineage, one of them being randomly chosen as a source of inoculum for the next passage. The capacity of the PVY population corresponding to the 15 lineages to infect the W4 pepper genotype was determined after the third, sixth, and eighth passages by manual inoculation to $10 \mathrm{~W} 4$ plants. Direct sequencing of RT-PCR fragments covering the entire $\mathrm{NIb}$ cistron of the virus populations was performed for the two initial inocula and for the 15 lineages after the seventh passage in YW plants.

\section{Modeling the structure of Potyvirus NIb proteins.}

Protein secondary structures were predicted using the PSIPRED server (Bryson et al. 2005). The tertiary structure of the NIb protein of the isolates SON41p and SON41p- $\mathrm{A}_{8424} \mathrm{G}$ of PVY and of TEV were performed on the I-TASSER server (Zhang 2008) that combines template-based and ab initio modeling methods. Functional domains of the protein were assigned using amino acid alignment with the RdRp of RHDV (Kenneth 
et al. 2002), which shows $22 \%$ similarity with the NIb protein of PVY, and motifs in the NIb protein were defined according to polymerase motifs previously described (Poch et al. 1989; Koonin 1991; Hansen et al. 1997; O'Reilly and Kao 1998; Bruenn 2003). Amino acid sequence alignments of the entire $\mathrm{NIb}$ proteins of pepper Potyvirus spp. were performed with Promals3D (Pei et al. 2008) using default parameters and the three-dimensional structure of RHDV as template (Protein databank ID: 1khv). Putative functionally and structurally important residues were predicted with ConSeq version 1.1 (Berezin et al. 2004).

\section{ACKNOWLEDGMENTS}

We thank E. Hébrard for advice in protein structure modeling; V. Simon for excellent technical assistance; F. Fabre for comments on earlier versions of the manuscript; and the ANRT foundation and the companies Gautier Semences, Clause Vegetable Seeds, Vilmorin SA, Sakata Seeds Europe, and Rijk Zwaan for their financial support.

\section{LITERATURE CITED}

Ayme, V., Souche, S., Caranta, C., Jacquemond, M., Chadoeuf, J., Palloix, A., and Moury, B. 2006. Different mutations in the genome-linked protein VPg of Potato virus $Y$ confer virulence on the $p v r 2^{3}$ resistance in pepper. Mol. Plant-Microbe Interact. 19:557-563.

Ayme, V., Petit-Pierre, J., Souche, S., Palloix, A., and Moury, B. 2007. Molecular dissection of the Potato virus $Y \mathrm{VPg}$ virulence factor reveals complex adaptations to the pvr2 resistance allelic series in pepper. J. Gen. Virol. 88:1594-1601.

Bendahmane, A., Kohm, B. A., Dedi, C., and Baulcombe, D. C. 1995. The coat protein of potato virus $\mathrm{X}$ is a strain-specific elicitor of Rx1-mediated virus resistance in potato. Plant J. 8:933-941.

Berezin, C., Glaser, F., Rosenberg, Y., Paz, I., Pupko, T., Fariselli, P., Casadio, R., and Ben-Tal, N. 2004. ConSeq: The identification of functionally and structurally important residues in protein sequences. Bioinformatics 20:1322-1324.

Berzal-Herranz, A., De la Cruz, A., Tenllado, F., Díaz-Ruiz, J. R., López, L., Sanz, A. I., Vaquero, C., Serra, M. T., and García-Luque, I. 1995. The Capsicum L3 gene-mediated resistance against the tobamoviruses is elicited by the coat protein. Virology 209:498-505.

Bruenn, J. A. 2003. A structural and primary sequence comparison of the viral RNA-dependent RNA polymerases. Nucleic Acids Res. 31:1821-1829.

Bryson, K., McGuffin, L. J., Marsden, R. L., Ward, J. J., Sodhi, J. S., and Jones, D. T. 2005. Protein structure prediction servers at University College London. Nucleic Acids Res. 33:W36-W38.

Carrasco, P., de la Iglesia, F., and Elena, S. F. 2007. Distribution of fitness and virulence effects caused by single-nucleotide substitutions in $T o$ bacco etch virus. J. Virol. 81:12979-12984.

Culver, J. N., Stubs, G., and Dawson, W. O. 1994. Structure-function relationship between tobacco mosaic virus coat protein and hypersensitivity in Nicotiana sylvestris. J. Mol. Biol. 242:130-138.

Dogimont, C., Palloix, A., Daubèze, A.-M., Marchoux, G., Gebre-Selassie, K., and Pochard, E. 1996. Genetic analysis of broad spectrum resistance to potyviruses in haplodiploid progenies of pepper (Capsicum annuиm L.). Euphytica 88:231-239.

Drake, J. W., and Holland, J. J. 1999. Mutation rates among RNA viruses. Proc. Natl. Acad. Sci. U.S.A. 96:13910-13913.

Fabre, F., Bruchou, C., Palloix, A., and Moury, B. 2009. Key determinants of resistance durability to plant viruses: Insights from a model linking within- and between-host dynamics. Virus Res. 141:140-149.

Fellers, J. P., Tremblay, D., Handest, M. F., and Lommel, S. A. 2002. The Potato virus $Y$ MsNr NIb-replicase is the elicitor of a veinal necrosishypersensitive response in root knot nematode resistant tobacco. Mol. Plant Pathol. 3:145-152.

García-Arenal, F., Fraile, A., and Malpica, J. M. 2001. Variability and genetic structure of plant virus populations. Annu. Rev. Phytopathol. 39:157-186

Gebre-Selassie, K., Marchoux, G., Delecolle, B., and Pochard, E. 1985. Variabilité naturelle des souches du virus $\mathrm{Y}$ de la pomme de terre dans les cultures de piment du sud-est de la France. Caractérisation et classification en pathotypes. Agronomie 5:621-630.

Gómez, P., Rodríguez-Hernández, A. M., Moury, B., and Aranda, M. A. 2009. Genetic resistance for the sustainable control of plant virus diseases: Breeding, mechanisms and durability. Eur. J. Plant Pathol. 125:122.
Hajimorad M. R., and Hill, J. H. 2001. Rsv1-mediated resistance against Soybean mosaic virus-N is hypersensitive response-independent at inoculation site, but has the potential to initiate a hypersensitive responselike mechanism. Mol. Plant-Microbe Interact. 14:587-598.

Hansen, J. L., Long, A. M., and Schultz, S. C. 1997. Structure of the RNAdependent RNA polymerase of poliovirus. Structure 5:1109-1122.

Harrison, B. D. 2002. Virus variation in relation to resistance breaking in plants. Euphytica 124:181-192.

Janzac, B., Fabre, F., Palloix, A., and Moury, B. 2009a. Constraints on evolution of virus avirulence factors predict the durability of corresponding plant resistances. Mol. Plant Pathol. 10:599-610.

Janzac, B., Fabre, M.-F., Palloix, A., and Moury, B. 2009b. Mechanism and spectrum of action of the Pvr4 resistance in pepper against potyviruses and selection of virulent variants. Plant Pathol. 58:443-449.

Jenner, C. E., Wang, X., Ponz, F., and Walsh, J. A. 2002. A fitness cost for Turnip mosaic virus to overcome host resistance. Virus Res. 86:1-6.

Kang, B.-C., Yeam, I., and Jahn, M. M. 2005. Genetics of plant virus resistance. Annu. Rev. Phytopathol. 43:581-621.

Kenneth, K. S., Cherney, M. M., Lopez Vazquez, A., Machin, A., Alonso, J. M. M., Parra, F., and James, M. N. G. 2002. Crystal structures of active and inactive conformations of a caliciviral RNA-dependent RNA polymerase. J. Biol. Chem. 277:1381-1387

Kimura, M. 1983. The Neutral Theory of Molecular Evolution. Cambridge University Press, Cambridge.

Köhm, B. A., Goulden, M. G., Gilbert, J. E., Kavanagh, T. A., and Baulcombe, D. C. 1993. A potato virus X resistance gene mediates an induced, nonspecific resistance in protoplasts. Plant Cell 5:913-620.

Koonin, E. V. 1991. The phylogeny of RNA-dependent RNA polymerases of positive-strand RNA viruses. J. Gen. Virol. 72:2197-2206.

Kyle, M., and Palloix, A. 1997. Proposed revision of nomenclature for potyvirus resistance genes in Capsicum. Euphytica 97:183-188.

Leach, J. E., Vera Cruz, C. M., Bai, J., and Leung, H. 2001. Pathogen fitness penalty as a predictor of durability of disease resistance genes. Annu. Rev. Phytopathol. 39:187-224.

Lecoq, H., Moury, B., Desbiez, C., Palloix, A., and Pitrat, M. 2004. Durable virus resistance in plants through conventional approaches: A challenge. Virus Res. 100:31-39.

Légnani, R., Gebre-Selassie, K., Nono-Womdim, R., Gognalons, P., Moretti, A., Laterrot, H., and Marchoux, G. 1995. Evaluation and inheritance of the Lycopersicon hirsutum resistance against potato virus Y. Euphytica 86:219-226.

Meshi, T., Motoyoshi, F., Maeda, T., Yoshiwoka, S., Watanabe, H., and Okada, Y. 1989. Mutations in the tobacco mosaic virus $30-\mathrm{kD}$ protein gene overcome Tm-2 resistance in tomato. Plant Cell 1:515-522.

Michaels, S. D., and Amasino, R. M. 1998. A robust method for detecting single-nucleotide changes as polymorphic markers by PCR. Plant J. 14:381-385.

Moury, B., Morel, C., Johansen, E., Guilbaud, L., Souche, S., Ayme, V., Caranta, C., Palloix, A., and Jacquemond, M. 2004. Mutations in Potato virus $Y$ genome-linked protein determine virulence toward recessive resistances in Capsicum annuиm and Lycopersicon hirsutum. Mol. PlantMicrobe Interact. 17:322-329.

Moury, B., Desbiez, C., Jacquemond, M., and Lecoq, H. 2006. Genetic diversity of plant virus populations: Towards hypothesis testing in molecular epidemiology. Adv. Virus Res. 67:49-87.

Moury, B., Fabre, F., and Senoussi, R. 2007. Estimation of the number of virus particles transmitted by an insect vector. Proc. Natl. Acad. Sci. U.S.A. 104:17891-17896.

Murant, A. F., Taylor, C. E., and Chambers, J. 1968. Properties, relationships and transmission of a strain of raspberry ringspot virus infecting raspberry cultivars immune to the common Scottish strain. Ann. Appl. Biol. 61:175-186.

Neff, M. M., Neff, J. D., Chory, J., and Pepper, A. E. 1998. dCAPS, a simple technique for the genetic analysis of single nucleotide polymorphisms: Experimental applications in Arabidopsis thaliana genetics. Plant J. 14:387-392.

O'Reilly, K. E., and Kao, C. C. 1998. Analysis of RNA-Dependent RNA polymerase structure and function as guided by known polymerase structures and computer predictions of secondary structure. Virology 252:287-303

Paran, I., Van Der Voort, J. R., Lefebvre, V., Jahn, M., Landry, L., Van Schriek, M., Tanyolac, B., Caranta, C., Ben Chaim, A., Livingstone, K. Palloix, A., and Peleman, J. 2004. An integrated genetic linkage map of pepper (Capsicum spp.). Mol. Breed. 13:251-261.

Pei, J., Kim, B.-H., and Grishin, N. V. 2008. PROMALS3D: A tool for multiple sequence and structure alignment. Nucleic Acids Res. 36:2295-2300.

Pelham, J., Fletcher, J. T., and Hawkins, J. H. 1970. The establishment of a new strain of tobacco mosaic virus resulting from the use of resistant varieties of tomato. Ann. Appl. Biol. 65:293-297. 
Poch, O., Sauvaget, I., Delarue, M., and Tordo, N. 1989. Identification of four conserved motifs among the RNA-dependent polymerase encoding elements. EMBO (Eur. Mol. Biol. Organ.) J. 8:3867-3874.

Sacristán, S., and García-Arenal, F. 2008. The evolution of virulence and pathogenicity in plant pathogen populations. Mol. Plant Pathol. 9:369384.

Salathé, M., Scherer, A., and Bonhoeffer, S. 2005. Neutral drift and polymorphism in gene-for-gene systems. Ecol. Lett. 8:925-932.

Sambrook, J., Fritsch, E. F., and Maniatis, T. 1989. Molecular Cloning: A Laboratory Manual, 2nd ed. Cold Spring Harbor Laboratory Press, Cold Spring Harbor, NY, U.S.A.
Thompson, J. D., Higgins, D. G., and Gibson, T. J. 1994. CLUSTAL W: Improving the sensitivity of progressive multiple sequence alignment through sequence weighting, position-specific gap penalties and weight matrix choice. Nucleic Acids Res. 22:4673-4680.

Vera Cruz, C. M., Bai, J., Ona, I., Leung, H., Nelson, R. J., Mew, T. W., and Leach, J. E. 2000. Predicting durability of a disease resistance gene based on an assessment of the fitness loss and epidemiological consequences of avirulence gene mutation. Proc. Natl. Acad. Sci. U.S.A. 97:13500-13505.

Zhang, Y. 2008. I-TASSER server for protein 3D structure prediction. BMC Bioinf 9:40. 